Check for updates

Cite this: RSC Adv., 2018, 8, 26563

\title{
Preparation of carbon-based hybrid particles and their application in microcellular foaming and flame-retardant materials
}

\author{
Zhicai He, (D) $\dagger^{a}$ Zhengping Zhao, $\dagger^{\mathrm{b}}$ Shengwei Xiao, ${ }^{* a}$ Jintao Yang $^{\mathrm{c}}$ \\ and Mingqiang Zhong*c
}

Polymeric microcellular foams with high strength and light weight are very important for industrial applications. However, regulating their cell structure and their weak flame retardancy are problematic. We designed single-arm POSS-based ionic liquids ([bel-POSS][PF 6 ), and constructed hybrid composites based on physical interaction between ionic liquids and carbon-based materials in PS microcellular foaming. Ionization of bel-POSS could result in a quaternary ammonium reaction and ion-exchange reaction, and the carbon materials exhibit good dispersion through blending. The prepared hybrid composites showed high $\mathrm{CO}_{2}$ adsorption. Conical calorimeter tests showed that PS composite materials could reduce the heat release rate, total heat release, toxic gases $\left(\mathrm{CO}_{2}\right.$ and $\left.\mathrm{CO}\right)$ release, and amount of smoke generated. These carbon materials could affect PS micropore structure, including the cell diameter and density. Upon addition of $5 \mathrm{wt} \%$ of carbon materials, the hole diameter decreased by $>50 \%$, and the hole density increased nearly ten folds.

Received 10th April 2018

Accepted 27th June 2018

DOI: $10.1039 / c 8 r a 03007 c$

rsc.li/rsc-advances flame retardancy; (ii) explore high-performance polymer microporous foams that integrate structural regulation, functionalization, and flame retardancy using carbon materials.

During the foaming of composite materials, the dispersion of carbon materials has a decisive role in heterogeneous nucleation, functionalization and flame retardancy. ${ }^{\mathbf{1 0 , 1 1}}$ Usually, carbon materials tend to agglomerate due to van der Waals forces unless modified through chemical grafting ${ }^{\mathbf{1 2 - 1 4}}$ and physical blending. ${ }^{15-17}$ Chemical modification can damage the structure and function of carbon materials, and such modification enhances complexity simultaneously. The efficiency of flame retardants is inhibited significantly if carbon materials are added to a single flame-retardant system. Based on these disadvantages, it is necessary to introduce other flame retardants to achieve synergistic flame retardancy. For example, grafting or loading hexachlorocyclotriphosphazene (HCCP), octa(aminophenyl) caged silsesquioxane, or $\mathrm{Ni}-\mathrm{Fe}$ layered double hydroxide on the surface of graphene oxide (GO) can induce GO catalytic carbonization and capture free radicals. ${ }^{12,18,19}$ Studies have revealed that polyhedral oligomeric silsesquioxane (POSS) and ionic liquids (ILs) exhibit $\mathrm{CO}_{2}$-philic and heterogeneous nucleation, ${ }^{20}$ which can improve the cell structure. POSS and ILs show good thermal stability and flame retardancy, which can reduce heat release during combustion and promote the formation of a highly antioxidant cracking layer.

Based on the studies above, we designed and fabricated a hybrid system by coupling carbon materials with POSS to maintain the complete structure of carbon materials. This as-
College of Medicine and Chemical Engineering, Taizhou University, Taizhou 318000 Tel: +8657688660177

${ }^{b}$ Zhijiang College, Zhejiang University of Technology, Hangzhou 310014, P. R. China ${ }^{c}$ College of Materials Science and Engineering, Zhejiang University of Technology, Hangzhou 310014, P. R. China. E-mail: zhongmingqiang@hotmail.com; Fax: +86 571 88320856; Tel: +86 57188320856

$\dagger$ Co-first author. 
prepared hybrid system was used for supercritical $\mathrm{CO}_{2}\left(\mathrm{scCO}_{2}\right)$ microporous foaming. We hoped that this strategy would lead to local enrichment of $\mathrm{CO}_{2}$ on carbon materials, improve heterogeneous nucleation efficiency, regulate cell structure, and allow the synergistic flame retardancy of POSS and carbon nanoparticles to be realized. To achieve this concept, physical interaction was established between POSS and carbon materials to enable effective combination and structural regulation. Fortunately, the coexistence of $\pi-\pi$ conjugation and $\pi$-cations enabled tight interactions between ILs and carbon materials. ${ }^{21}$ POSS-based ILs were designed, synthesized and characterized. The $\pi-\pi$ and $\pi$-cation interactions between ILs and carbon nanoparticles were used to construct carbon-based hybrid materials, and their dispersion, $\mathrm{scCO}_{2}$ enrichment, nucleating efficient, and flame retardancy were investigated. The integration between cell-structure regulation and flame retardancy could provide new perspectives for fabricating multi-functional microporous foaming materials.

\section{Experimental}

\subsection{Materials}

Chlorobenzylethyllsobutyl POSS $\left(\mathrm{C}_{37} \mathrm{H}_{73} \mathrm{O}_{12} \mathrm{Si}_{8}\right.$, FW 970.11) was purchased from Hybrid Plastics (Hattiesburg, MI, USA) and was used as received. Carbon nanotubes (CNTs), GO, sodium iodide (NaI), triethylamine (TEA), potassium hexafluorophosphate $\left(\mathrm{KPF}_{6}\right)$, hydrazine monohydrate and styrene $(\mathrm{St})$ were obtained from Aladdin Reagents (Shanghai, China). Acetonitrile $\left(\mathrm{CH}_{3} \mathrm{CN}\right)$ was purchased from Shanghai Ling Feng Chemical Reagents (Shanghai, China) and was used as received. Polystyrene (PS) was obtained from Zhenjiang Qi Mei Chemicals (Zhenjiang, China). $\mathrm{CO}_{2}$ was supplied by Hangzhou Jingong Gas (Hangzhou, China).

\subsection{Sample preparation}

2.2.1 Synthesis of POSS-based IL. Benzylethyllsobutyl POSS hexafluorophosphate ([bel-POSS $\left.]\left[\mathrm{PF}_{6}\right]\right)(2.9103 \mathrm{~g}, 3 \mathrm{mmol})$ and $300 \mathrm{~mL}$ of $\mathrm{CH}_{3} \mathrm{CN}$ were added to a flask equipped with a magnetic stirrer. After complete dissolution of the powder, TEA ( $3.036 \mathrm{~g}, 30 \mathrm{mmol})$ and NaI $(0.4497 \mathrm{~g}, 3 \mathrm{mmol})$ were added to the solution mentioned above. The mixed reactants were stirred for $24 \mathrm{~h}$ at $82{ }^{\circ} \mathrm{C}$, and then $\mathrm{KPF}_{6}(3.036 \mathrm{~g}, 30 \mathrm{mmol})$ was added to the reaction at $82{ }^{\circ} \mathrm{C}$ for $24 \mathrm{~h}$ under magnetic stirring. After completion of the reaction, the solvent was removed by vacuum distillation. A white powder was collected after water washing and dried in a vacuum at $80{ }^{\circ} \mathrm{C}$ for $24 \mathrm{~h}(3.3547 \mathrm{~g}$, 94.7\%). The synthetic route is shown in Fig. 1.

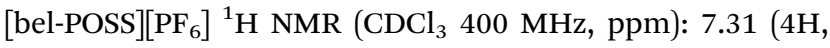
$\mathrm{Ph}), 4.32$ (2H, N- $\left.\mathrm{CH}_{2}-\mathrm{Ph}\right), 3.25\left(6 \mathrm{H}, \mathrm{N}-\mathrm{CH}_{2}-\right), 1.58$ (7H, $-\mathrm{CH}-$ $\left.\mathrm{Me}_{2}\right), 1.47\left(9 \mathrm{H}, \mathrm{CH}_{3}, \mathrm{~N}-\left(\mathrm{CH}_{2} \mathrm{CH}_{3}\right)_{3}\right), 1.27\left(2 \mathrm{H},-\mathrm{CH}_{2}-\mathrm{Ph}\right), 0.98$ $\left(42 \mathrm{H},-\mathrm{CH}_{3}\right), 0.63\left(14 \mathrm{H}, \mathrm{Si}-\mathrm{CH}_{2}-\right)$.

Mass spectra (MS data): (electrospray ionization, ESI + ) $\mathrm{m} / \mathrm{z}$ 1034.5 [bel-POSS $]^{+},(\mathrm{ESI}-) \mathrm{m} / z 145.0\left[\mathrm{PF}_{6}\right]^{-}$.

2.2.2 Preparation of CNTs hybrid materials and RGO hybrid materials. A typical process for the fabrication of RGO hybrid materials was followed. For [bel-POSS][ $\left.\mathrm{PF}_{6}\right] / \mathrm{RGO}, 0.3 \mathrm{~g}$ of
$\mathrm{GO}$ and $300 \mathrm{~mL}$ of deionized water were added to a $500 \mathrm{~mL}$ flask equipped with magnetic stirring. Uniform dispersion of GO solution in deionized water was achieved by ultrasonic treatment. Then, $0.6 \mathrm{~g}$ of [bel-POSS] $\left[\mathrm{PF}_{6}\right]$ and $3 \mathrm{~mL}$ of hydrazine monohydrate were added to the suspension and magnetic stirring was carried out at $100{ }^{\circ} \mathrm{C}$ for $24 \mathrm{~h}$. After completion of the reaction, the solvent was removed by centrifugation and the black powder was collected, water-washed and dried in vacuum at $80{ }^{\circ} \mathrm{C}$ for $24 \mathrm{~h}(0.8551 \mathrm{~g}, 95.01 \%)$.

The preparation of CNTs hybrid materials was similar to that of RGO hybrid materials except that RGO replaced CNTs and hydrazine was not added. Fig. 2 illustrates a typical synthetic route of CNTs hybrid materials and RGO hybrid materials.

2.2.3 Preparation PS composites. Pure PS and PS composites were made into cylindrical bars using a micro twin-screw extruder operating at $190{ }^{\circ} \mathrm{C}$.

2.2.4 $\mathrm{scCO}_{2}$ foaming process. A batch foaming process was conducted in a high-pressure vessel. The samples was placed in a vessel filled with $\mathrm{CO}_{2}$ and saturated at $100{ }^{\circ} \mathrm{C}$ and $13.8 \mathrm{MPa}$ for $12 \mathrm{~h}$. Then, the pressure was released rapidly in $0.5 \mathrm{~s}$ and foam morphology fixed by cooling in an ice-water mixture.

\subsection{Measurement and characterization}

${ }^{1} \mathrm{H}$ NMR spectra were measured on an AVANCE III (500M) NMR spectrometer (Bruker, Billerica, MA, USA) using $\mathrm{CDCl}_{3}$ as the solvent. Molecular weight was determined on a 6210 time of flight liquid chromatography/mass spectrometry (TOF LC/MS) system (Agilent Technologies, Santa Clara, CA, USA) using $\mathrm{CH}_{3} \mathrm{CN}$ as the solvent. Fourier transform infrared (FT-IR) spectra were recorded on a Nicolet 6700 IR spectrometer (Thermo Scientific, Waltham, MA, USA) with a continuum microscope. The glass transition temperature $\left(T_{\mathrm{g}}\right)$ of pure PS and PS composites was measured by differential scanning calorimetry (DSC) using a TA-Q100 system (TA Instruments, New Castle, DE, USA). For DSC measurement, $10 \mathrm{mg}$ of sample in an aluminum crucible was heated from $40{ }^{\circ} \mathrm{C}$ to $280{ }^{\circ} \mathrm{C}$ at $10^{\circ} \mathrm{C} \mathrm{min}^{-1}$ under $\mathrm{N}_{2}$ flow of $10 \mathrm{~mL} \mathrm{~min}^{-1}$. The heat release rate of pure PS and PS composites was measured by a cone calorimeter. A two-roll mill and press machine was used for sample preparation $\left(100 \times 100 \times 2 \mathrm{~mm}^{3}\right)$. A flame-retardancy test was done on a cone calorimeter (Stanton Redcroft, London, UK). The test standard was ISO 5660 with heat flux of $35 \mathrm{~kW} \mathrm{~m}^{-2}$. The morphology of pure PS and PS composites was observed by scanning electron microscopy (SEM) using an S-4700 system (Hitachi, Tokyo, Japan). Samples were fractured in liquid nitrogen, and the fracture surface was sputter-coated with $\mathrm{Au}$. Images were acquired at an accelerating voltage of $10 \mathrm{kV}$ and a working distance of $8 \mathrm{~mm}$.

The high-pressure solubility of $\mathrm{CO}_{2}$ in pure PS and PS composites was measured by a gravimetric method. Samples were saturated by $\mathrm{CO}_{2}$ at $13.8 \mathrm{MPa}$ and $35^{\circ} \mathrm{C}$. Then, they were removed rapidly from the vessel for weighing, and the mass losses of samples with time were recorded. The $\mathrm{CO}_{2}$ solubility of carbon hybrid particles at atmospheric pressure was measured by a thermogravimetric analyzer (SDT Q600; TA Instruments). Samples in aluminum crucibles were at $40{ }^{\circ} \mathrm{C}$ for 60 min under 
<smiles></smiles>

bel-POSS

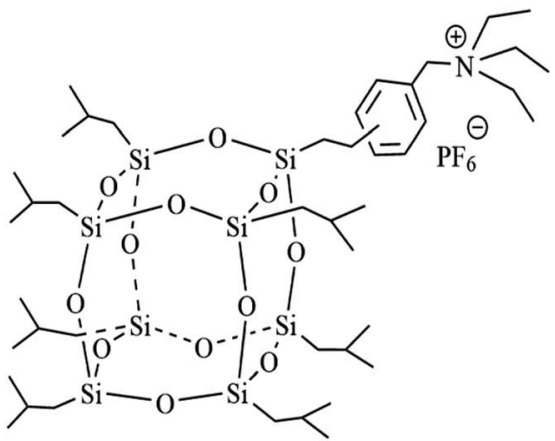

[bel-POSS][PF 6 ]

Fig. 1 Synthesis of [bel-POSS] $\left[\mathrm{PF}_{6}\right]$.

$\mathrm{CO}_{2}$ flow of $10 \mathrm{~mL} \mathrm{~min}{ }^{-1}$, and the weight gain of samples with time was recorded.

The average cell diameter and cell density were calculated using DigitalMicrograph $\circledast$ (Gatan, Pleasanton, CA, USA) software. Non-circular cells were assumed to have a circular shape when calculating sizes. The cell density $\left(N_{0}\right)$ is the number of cells per cubic centimeter of foamed samples, and was determined using the following formula:

$$
N_{0}=\frac{6\left(1-\rho_{\mathrm{f}} / \rho\right)}{\pi D^{3}}
$$

where $D$ is the average cell diameter, $\rho_{\mathrm{f}}$ is the density of the foam sample measured according to the American Society for Testing Materials (ASTM-D792), and $\rho$ is the density of the unfoamed sample $\left(\rho_{\mathrm{PS}}=1.04 \mathrm{~g} \mathrm{~cm}^{-3}\right)$.

\section{Results and discussion}

\subsection{Characterization of POSS-based IL and hybrid particles}

The pure POSS-based IL ([bel-POSS][$\left[\mathrm{PF}_{6}\right]$ ) was synthesized by combination of a quaternization reaction and ion-exchange reaction. Then, a hydrazine-monohydrate reduction method and solution blending were applied to prepare RGO hybrid materials and CNTs hybrid materials, respectively. Fig. 3 displays the FT-IR spectra of as-obtained hybrid materials. For pure sin POSS, the characteristic peaks at $744 \mathrm{~cm}^{-1}$ and $1100 \mathrm{~cm}^{-1}$ were attributed to $\mathrm{CH}_{2}-\mathrm{Cl}$ and $\mathrm{Si}-\mathrm{O}-\mathrm{Si}$, respectively. A characteristic peak at $2975 \mathrm{~cm}^{-1}$ was attributed to the stretching vibration of surface-adsorbed $\mathrm{CO}_{2}$. For [bel-POSS] $\left[\mathrm{PF}_{6}\right]$, the intensity of the characteristic peak at $744 \mathrm{~cm}^{-1}$ was smaller, which was due mainly to the quaternization of $\mathrm{CH}_{2}-\mathrm{Cl}$. This result revealed that [bel-POSS][Cl] was synthesized with the feature of an unspent $\mathrm{CH}_{2}-\mathrm{Cl}$ group. A new characteristic peak

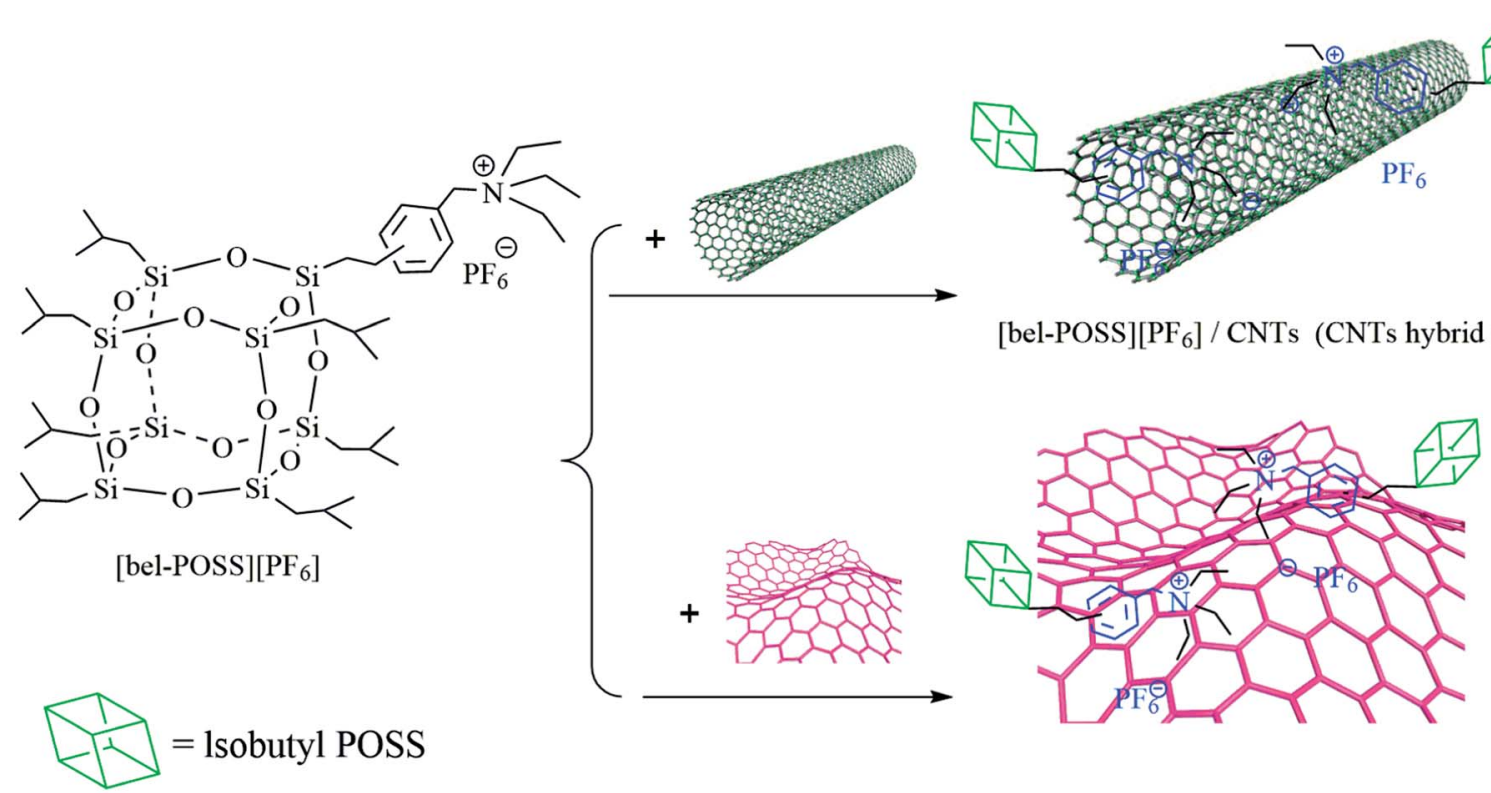

[bel-POSS][ $\left.\mathrm{PF}_{6}\right]$ / RGO (RGO hybrid particle)

Fig. 2 Preparation of carbon-based hybrid particles. 


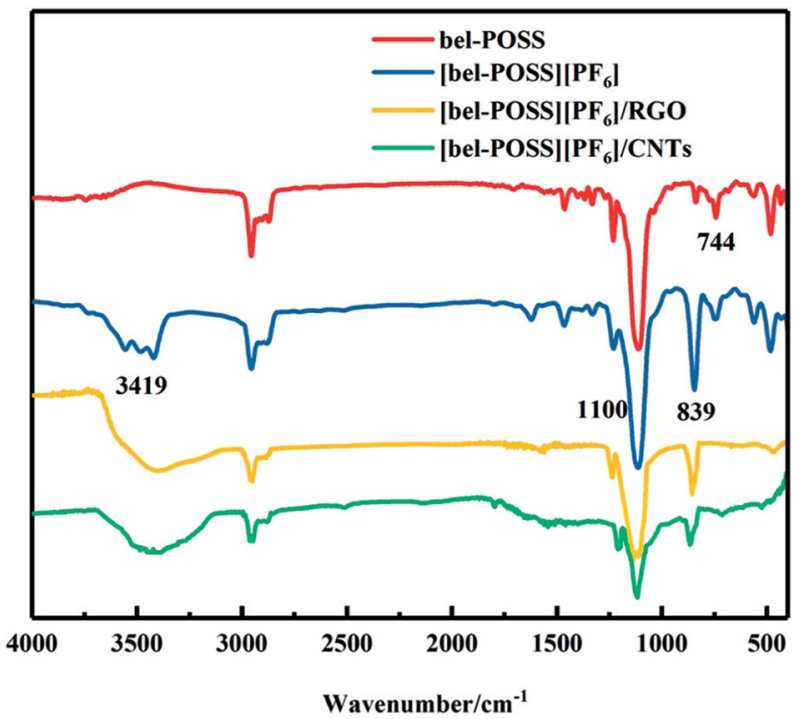

Fig. 3 FT-IR spectra of bel-POSS, [bel-POSS][PF 6 , [bel-POSS][PF 6 ]/ $\mathrm{RGO}$ and [bel-POSS] $\left[\mathrm{PF}_{6}\right] /$ CNTs.

ascribed to $\left[\mathrm{PF}_{6}\right]^{-}$appeared at $839 \mathrm{~cm}^{-1}$, which was an indicator of an ion-exchange reaction between [bel-POSS][Cl] and $\mathrm{KPF}_{6}$. This result further confirmed that [bel-POSS $]\left[\mathrm{PF}_{6}\right]$ had been prepared. Hydrazine hydrate-reduced RGO hybrid materials and CNTs hybrid materials exhibited similar FT-IR spectra with that of [bel-POSS][ $\left.\mathrm{PF}_{6}\right]$, which showed the hydroxyl groups on GO were reduced and carbon materials (RGO and CNTs) and [bel-POSS $]\left[\mathrm{PF}_{6}\right]$ had combined physically.

The influence of RGO hybrid materials and CNTs hybrid materials on the thermal properties of PS were demonstrated using DSC. The DSC curves of pure PS, [bel-POSS $]\left[\mathrm{PF}_{6}\right]$ and composite materials are shown in Fig. 4. The $T_{\mathrm{g}}$ (which represents the upper temperature for polymer application) was obtained from DSC curves. The $T_{\mathrm{g}}$ of pure PS was $105.1^{\circ} \mathrm{C}$, and [bel-POSS $]\left[\mathrm{PF}_{6}\right]$ had good heat resistance and melted directly at $232.3{ }^{\circ} \mathrm{C}$. Upon combination of the PS composites of hybrid

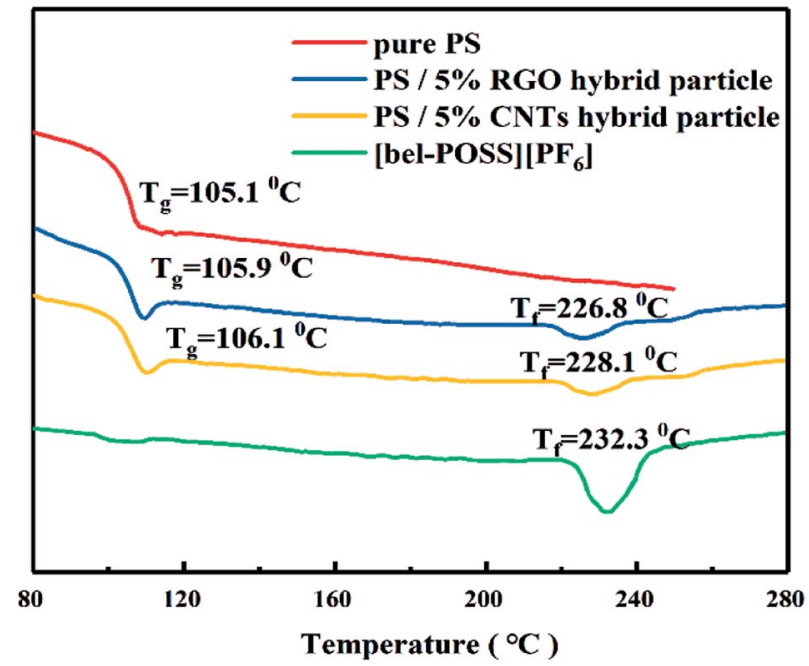

Fig. 4 DSC curves of pure PS, PS/5\% RGO hybrid particle, PS/5\% CNTs hybrid particle and [bel-POSS] $\left.\mathrm{PF}_{6}\right]$. particles and [bel-POSS] $\left.\mathrm{PF}_{6}\right]$, the $T_{\mathrm{g}}$ of the corresponding composites was between the $T_{\mathrm{g}}$ of pure PS and that of [belPOSS $]\left[\mathrm{PF}_{6}\right]$. When $5 \mathrm{wt} \%$ of the RGO hybrid particle was used, the $T_{\mathrm{g}}$ of the composite was $105.9{ }^{\circ} \mathrm{C}$ (about $0.8{ }^{\circ} \mathrm{C}$ higher than that of pure PS) and another melting temperature appeared at $226.8{ }^{\circ} \mathrm{C}$, which was attributed to the effect of [bel-POSS] $\left[\mathrm{PF}_{6}\right]$. A similar trend for the $T_{\mathrm{g}}$ of PS/5\% CNTs hybrid particle was observed when a $5 \mathrm{wt} \%$ CNTs hybrid particle was employed, and the $T_{\mathrm{g}}$ of the composite was $106.1{ }^{\circ} \mathrm{C}$, and the fictive temperature $\left(T_{\mathrm{f}}\right)$ was $228.1{ }^{\circ} \mathrm{C}$. Generalized compatibility theory suggests that partially compatible systems have two $T_{\mathrm{g}}$ values, that the two $T_{\mathrm{g}}$ peaks are closer than the $T_{\mathrm{g}}$ peak of each polymer, and that there is a certain degree of diffusion of molecules (or segments) between the two phases. Therefore, there is a certain compatibility between PS, RGO hybrid particles and CNTs hybrid particles, and the hybrid particles can be well dispersed in PS.

\section{2 $\mathrm{CO}_{2}$ adsorption of carbon hybrids}

The atmospheric adsorption of $\mathrm{CO}_{2}$ by carbon hybrid materials was assessed by TGA. As shown in Fig. 5, when the hybrid particles were immersed in $\mathrm{CO}_{2}$, the weight of the samples increased gradually with increasing adsorption time. The two hybrid samples displayed a fast adsorption rate initially. As time increased, adsorption became slower. Comparison of the $\mathrm{CO}_{2}$ adsorption properties of graphene hybrids and CNTs hybrids revealed that the latter had a stronger adsorption effect on $\mathrm{CO}_{2}$ in comparison with graphene hybrid materials. Adsorption of CNTs hybrids was always greater than that of graphene hybrids. When the samples were soaked in $\mathrm{CO}_{2}$ for $1 \mathrm{~h}$, the $\mathrm{CO}_{2}$ adsorption rate of CNTs hybrid particles reached $3.25 \mathrm{wt} \%$, which was better than that of RGO hybrid materials (2.72 wt \%).

\subsection{Dispersion of carbon hybrid particles in styrene}

In general, to improve the dispersion of carbon materials in polymers, they are modified to reduce the tendency of van der

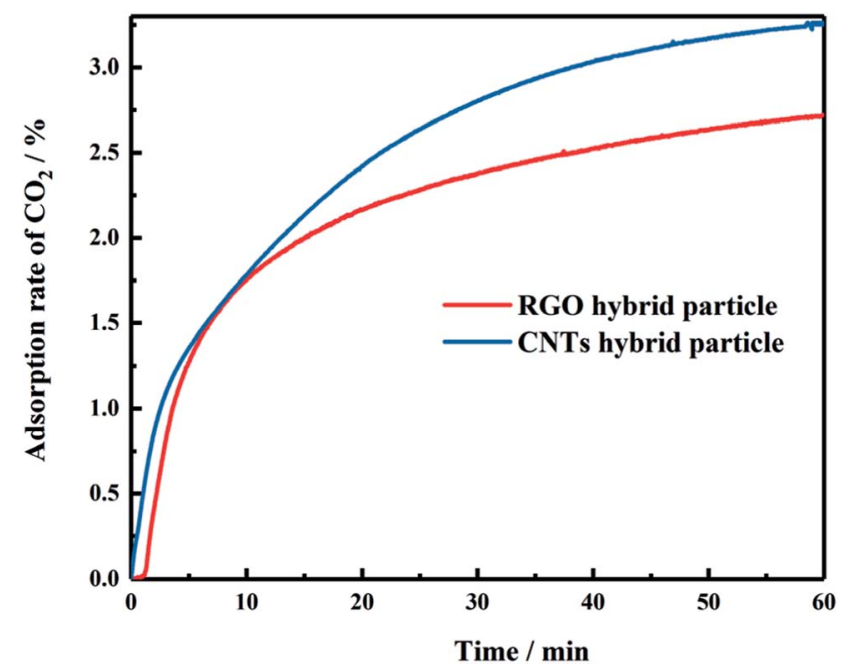

Fig. $5 \mathrm{CO}_{2}$ adsorption of carbon nanoparticle hybrid particles (1 atm, $40.0^{\circ} \mathrm{C}$ ). 


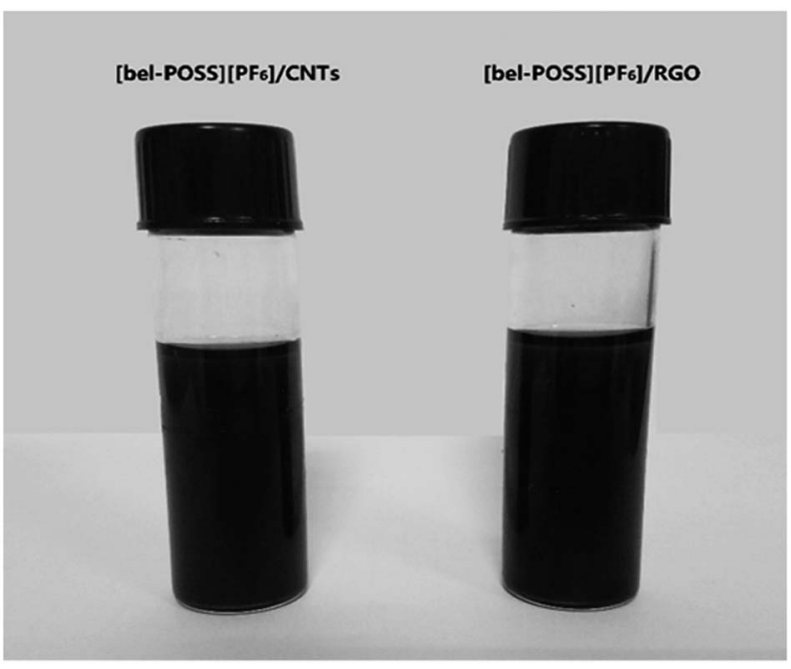

Fig. 6 Dispersion of carbon hybrid particles in styrene solution (12 h).

Waals forces to cause agglomeration. Hence, it is highly desired to use $\pi-\pi$ and $\pi$-cation interactions between singlearm POSS-based ILs and carbon materials. To investigate the dispersion of hybrid materials, the as-fabricated samples were dissolved in St solution (Fig. 6). After stewing for $12 \mathrm{~h}$, the [belPOSS $]\left[\mathrm{PF}_{6}\right] / \mathrm{CNTs}$ and [bel-POSS $]\left[\mathrm{PF}_{6}\right] / \mathrm{RGO}$ hybrid materials continued to exhibit uniform dispersion in the St solution with only slight delamination, indicating moderate compatibility between the carbon materials and St. This strategy facilitated the dispersion of carbon materials in the PS matrix, and acted as heterogeneous nucleation in the foaming process.

\section{4 $\mathrm{CO}_{2}$ absorption of pure PS and PS composites}

The solubility of $\mathrm{CO}_{2}$ in pure PS and the PS composites at room temperature was measured using a gravimetric method. Samples were saturated by $\mathrm{CO}_{2}$ at $13.8 \mathrm{MPa}$ at $350{ }^{\circ} \mathrm{C}$ for $12 \mathrm{~h}$ and then collected rapidly from the vessel for weighing. Mass losses of samples with time were recorded (Fig. 7). Pure PS, PS/5\% RGO hybrid materials and PS/5\% CNTs hybrid materials showed a linear relationship between the $\mathrm{CO}_{2}$ concentration and square root of desorption time. $\mathrm{CO}_{2}$ diffusion obeys Fick's law, so the initial solubility in pure PS and PS composites can be obtained (Fig. 7) through fitting and extrapolation of the curves. The initial solubility towards $\mathrm{CO}_{2}$ absorption using $\mathrm{PS} / 5 \%$ CNTs hybrid materials was $11.41 \%, 10.63 \%$ for $\mathrm{PS} / 5 \% \mathrm{RGO}$, and $10.63 \mathrm{wt} \%$ for pure PS, respectively. Enhancement of $\mathrm{CO}_{2}$ solubility could be attributed to the affinity of carbon materials and POSS-based IL. Moreover, the capacity for $\mathrm{CO}_{2}$ adsorption of CNTs hybrid materials was slightly better than that for RGO hybrid materials. $\mathrm{CO}_{2}$ desorption for pure PS was the slowest and only $3.75 \mathrm{wt} \% \mathrm{CO}_{2}$ was detached in $30 \mathrm{~min}$. The $\mathrm{CO}_{2}$ desorption rate was accelerated considerably when carbon materials were added into the PS matrix, with $5.78 \mathrm{wt} \%$ of

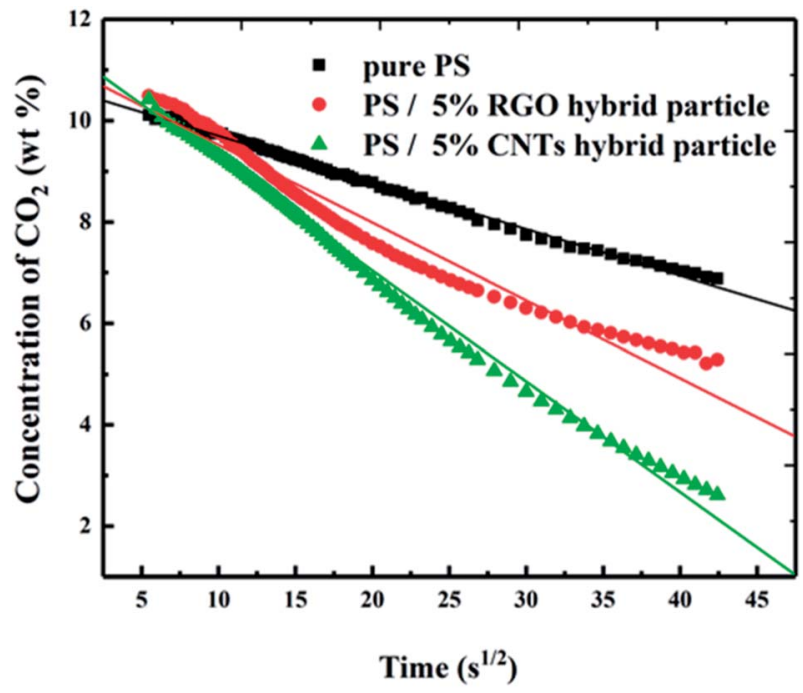

Fig. $7 \mathrm{CO}_{2}$ solubility in pure PS and PS composites (13.8 $\left.\mathrm{MPa}, 35^{\circ} \mathrm{C}\right)$.

$\mathrm{CO}_{2}$ being detached in PS/5\% RGO, and $8.80 \mathrm{wt} \%$ in CNTs hybrid materials.

\subsection{Flame retardancy of PS composites}

A carbon hybrid materials flame-retardant system was designed to improve its flame retardancy. Its heat release rate (HRR), total heat release (THR), ignition time (ITT), specific extinction area (SEA), $\mathrm{CO}_{2}$ release rate, and $\mathrm{CO}$ release rate were evaluated using a cone calorimeter. Fig. 8 shows the HRR and THR for pure PS and PS composites. Data from Fig. 8 show the peak heat release rate (pkHRR) for pure PS to be $1670.1 \mathrm{~kW} \mathrm{~m}^{-2}$, and THR to be $149.6 \mathrm{MJ} \mathrm{m}^{-2}$. After adding $5 \mathrm{wt} \%$ CNTs hybrid particles, the pkHRR and THR were reduced to $1068.5 \mathrm{~kW} \mathrm{~m}^{-2}$ and 94.4 $\mathrm{MJ} \mathrm{\textrm {m } ^ { - 2 }}$, respectively, a reduction of $36.02 \%$ and $36.9 \%$; addition of $5 \mathrm{wt} \%$ RGO hybrids reduced the values by $39.97 \%$ and $42.9 \%$, respectively.

Table 1 shows the ITT, pkHRR, THR, average specific extinction area (Av-SEA), peak $\mathrm{CO}_{2}$ release rate $\left(\mathrm{p}-\mathrm{CO}_{2}\right)$ and peak $\mathrm{CO}$ release rate (p-CO) for the cone calorimeter test. Data from Table 1 reveal that, after addition of carbon hybrid materials, the ITT of the composite material decreased slightly. That is, the time required for the material surface to be heated until the material continued to burn became shorter and the material became easier to burn. However, the HRR and total amount of heat released from the composite material were reduced significantly. This result suggested that the heat of combustion of the material was reduced, and that the fire risk was also reduced. The SEA denotes the smoke produced by a volatile material of unit mass, and the value of SEA is related positively to the amount of smoke produced. The Av-SEA of pure PS was $885 \mathrm{~m}^{2} \mathrm{~kg}^{-1}$, and that of CNTs hybrid and RGO hybrid materials decreased to $387 \mathrm{~m}^{2} \mathrm{~kg}^{-1}$ and $306 \mathrm{~m}^{2} \mathrm{~kg}^{-1}$, respectively. These findings suggested that carbon hybrid materials exhibited effective smoke suppression.

These data suggested that carbon hybrid materials could reduce the HRR of PS significantly and had good smoke- 

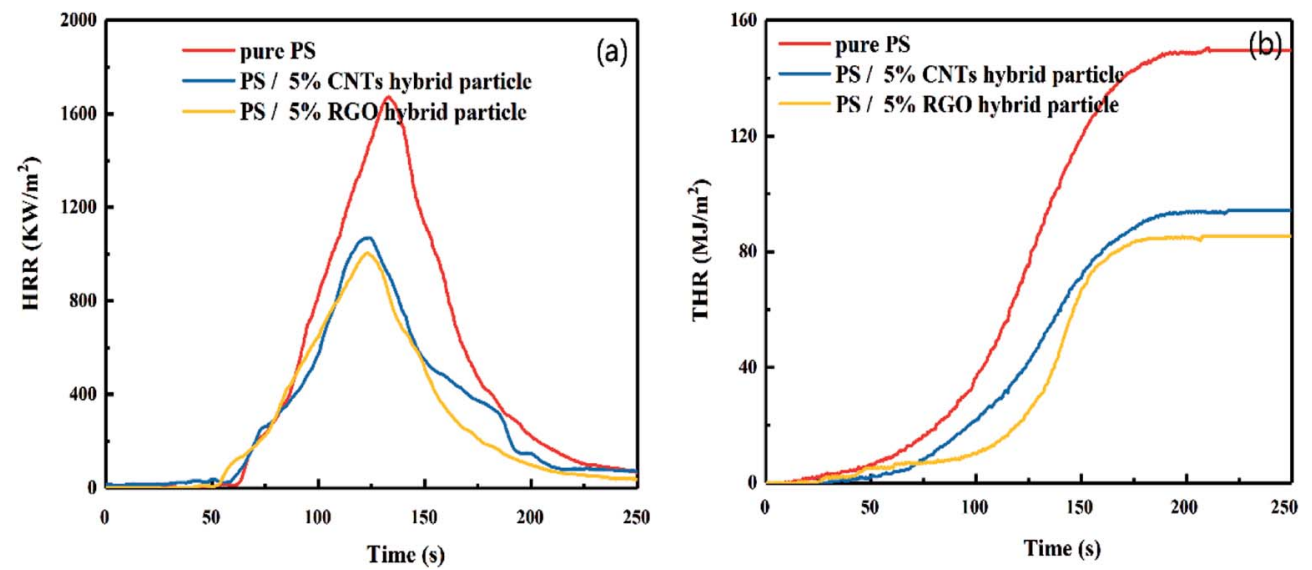

Fig. 8 The heat release rate (HRR) and total heat release (THR) of pure PS and PS composites.

suppression properties. POSS is an organosilicon flame retardant with catalytic-carbonization and smoke-suppression properties. ILs have a phosphorus-nitrogen synergistic effect. This effect is functionalized by releasing an inert gas to interfere with the combustion chain. This inhibits smoke generation during combustion, and the release of toxic gases $\left(\mathrm{CO}_{2}\right.$ and $\left.\mathrm{CO}\right)$ and Av-SEA are reduced significantly, thereby showing obvious vapor-phase flame retardancy. Carbon materials (CNTs and RGO) promote the formation of a uniform, dense, carbon-layer barrier when they burn, thereby preventing PS decomposition and heat transfer from the surface. Besides, the construction of carbon layer can prevent thermal-decomposition products within the material from entering the flame zone and outside simultaneously, which are the characteristic features of solidphase flame retardants.

\subsection{Foaming properties of PS composites}

We examined the effect of carbon hybrid materials on cell structure, especially the effect on nucleation efficiency. Therefore, pure $\mathrm{PS}, \mathrm{PS} / 5 \%$ CNTs hybrid particles, and PS $/ 5 \%$ RGO hybrid particles were foamed under identical conditions and the cell structure of each foamed sample compared. Fig. 9 shows the SEM images of pure PS and PS composites foamed under identical conditions; the average cell diameter, cell density, and foam density of these foams are shown in Table 2. The cell diameter of pure PS was significantly larger, and cell structures improved significantly, after addition of the carbon hybrid materials. Upon addition of 5\% CNTs hybrid particles, the cell diameter decreased to $2.79 \mu \mathrm{m}$, and the cell density increased to $5.70 \times 10^{10}$ cell per $\mathrm{cm}^{3}$. Addition of $5 \%$ RGO hybrid particles elicited similar results: the average cell diameter and cell density were $2.87 \mu \mathrm{m}$ and $5.54 \times 10^{10}$ cell per $\mathrm{cm}^{3}$, respectively. Addition of carbon hybrid particles resulted in a significant increase in the cell density of the foamed material and slightly increased foam density. The increase in cell density was due mainly to the increase in the number of cell nucleation sites, which resulted in a significant increase in the nucleation efficiency of composite materials. The increase in foam density was due mainly to the low expansion ratio of foam cells.

Pure PS foaming is primarily a homogeneous nucleation, the Gibbs free energy barrier $\left(\Delta G^{*}\right)$ is related mainly to the interfacial free energy $\left(\gamma_{\alpha \beta}\right)$ as well as the internal and external pressure difference $(\Delta P)$ of cells, so the nucleation efficiency is not high and the average cell diameter is large. Due to the role of carbon hybrid particles, PS composites can undergo homogeneous nucleation and heterogeneous nucleation. The latter is reflected mainly in two factors. The first factor is that the nucleation additive (CNTs hybrid particle and RGO hybrid particle) is $\mathrm{CO}_{2}$-philic; this will increase the surface contact angle $(\theta)$ between the blowing gas and solid particles and reduce the heterogeneous nucleation factor. According to nucleation theory, ${ }^{22}$ the heterogeneous nucleation factor and heterogeneous nuclear energy barrier will decrease, which is beneficial to heterogeneous nucleation efficiency. The second factor is an increase in the increase of nucleation sites. During the foaming process, [bel-POSS $]\left[\mathrm{PF}_{6}\right]$ and carbon nanoparticles (CNTs and RGO) are in the solid state, and can have a role in the number of heterogeneous nucleation points. Surface morphology, uniform surface modification, and uniform distribution of nucleating agents are also beneficial for heterogeneous nucleation. CNTs are typical one-

Table 1 Values using the cone calorimeter test

\begin{tabular}{lllllr}
\hline Sample name & ITT $(\mathrm{s})$ & $\begin{array}{l}\text { pkHRR } \\
\left(\mathrm{kW} \mathrm{m}^{-2}\right)\end{array}$ & $\begin{array}{l}\text { THR } \\
\left(\mathrm{MJ} \mathrm{m}^{-2}\right)\end{array}$ & $\begin{array}{l}\mathrm{Av-SEA} \\
\left(\mathrm{m}^{2} \mathrm{~kg}^{-1}\right)\end{array}$ & $\begin{array}{l}\mathrm{p}-\mathrm{CO} \\
\left(\mathrm{g} \mathrm{s}^{-1}\right)\end{array}$ \\
\hline Pure PS & & & & & $\begin{array}{l}\mathrm{p}-\mathrm{CO} \\
\left(\mathrm{g} \mathrm{s}^{-1}\right)\end{array}$ \\
PS/5\% CNTs & 60 & 1670.1 & 149.6 & 885 & 0.62 \\
PS/5\% RGO & 55 & 1068.5 & 94.4 & 387 & 0.018 \\
\end{tabular}



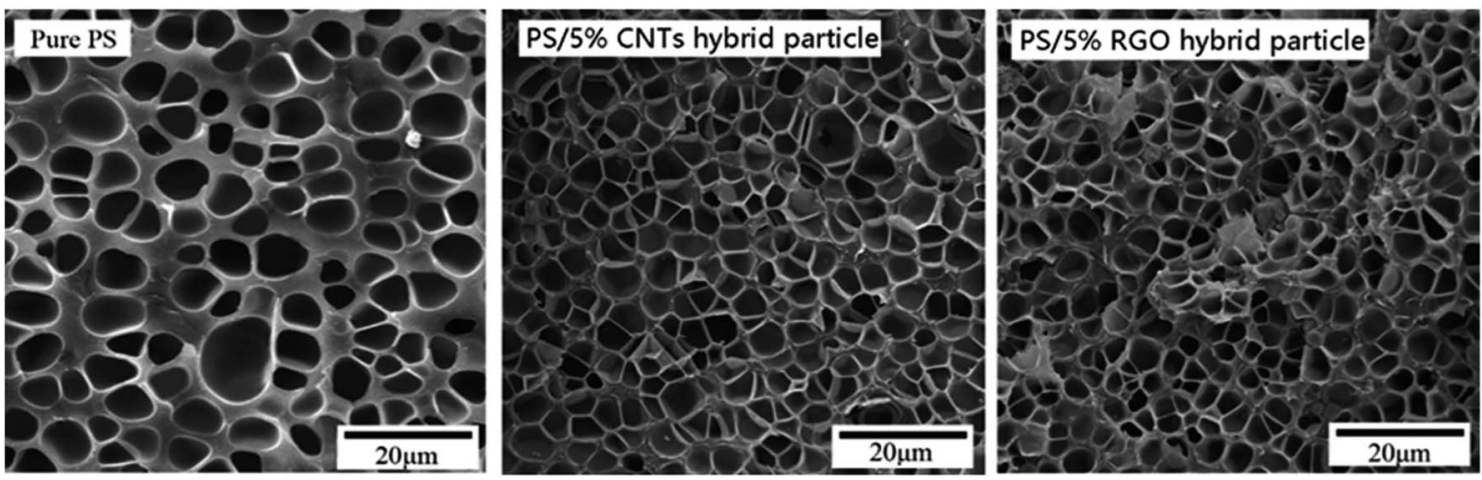

Fig. 9 SEM images of pure PS and PS composite foams $\left(100^{\circ} \mathrm{C}, 13.8 \mathrm{MPa}\right)$.

Table 2 Foam parameters of pure PS and PS composites $\left(100^{\circ} \mathrm{C}, 13.8 \mathrm{MPa}\right)$

\begin{tabular}{llll}
\hline Samples & $\begin{array}{l}\text { Average cell size } \\
(\mu \mathrm{m})\end{array}$ & $\begin{array}{l}\text { Cell density } \\
\left(\text { cell per } \mathrm{cm}^{3}\right)\end{array}$ & $\begin{array}{l}\text { Foam density } \\
\left(\mathrm{g} \mathrm{cm}^{-3}\right)\end{array}$ \\
\hline Pure PS & $6.16 \pm 1.89$ & $0.57 \times 10^{10}$ & 0.31 \\
PS/5\% CNTs hybrid particle & $2.79 \pm 0.66$ & $5.70 \times 10^{10}$ & 0.37 \\
PS/5\% RGO hybrid particle & $2.87 \pm 0.73$ & $5.54 \times 10^{10}$ & 0.33
\end{tabular}

dimensional carbon nanoparticles, RGOs are typical twodimensional carbon nanoparticles, and their regular surface morphologies are favorable for nucleation and growth; moreover, $\mathrm{CO}_{2}$ absorption on their surfaces promote nucleation.

\section{Conclusions}

We proposed a physical composite method using single-arm POSS-based ILs [bel-POSS][ $\left.\mathrm{PF}_{6}\right]$ and carbon materials (CNTs and RGO) to enhance PS flame retardancy and to regulate cell morphology. We demonstrated that single-arm POSS-based ILs could be prepared by quaternization and ion-exchange reaction. The hydrate reduction method using hydrazine could achieve physical recombination with carbon materials. On the basis of various characterizations, carbon hybrid materials were found to be $\mathrm{CO}_{2}$-philic and to have moderate compatibility with PS. Carbon hybrid materials had a dual role in the heterogeneous nucleation and adsorption of $\mathrm{CO}_{2}$ in this system. Addition of carbon materials into the PS matrix not only regulated the cell morphology of PS, it also achieved synergistic flame retardancy.

\section{Conflicts of interest}

There are no conflicts to declare.

\section{Acknowledgements}

This study was supported financially by the Zhejiang Province Public Welfare Project (2017C31112) and the National Natural Science Foundation of China (21504079).

\section{References}

1 J. Elsing, T. Stefanov, M. D. Gilchrist and C. Stubenrauch, Phys. Chem. Chem. Phys., 2017, 19(7), 5477-5485.

2 Y. Lei, T. Liu, Z. Chen, A. Lu, X. Wang and X. Zhao, RSC Adv., 2014, 4(37), 19103-19110.

3 B. Jeon, H. K. Kim, S. W. Cha, S. J. Lee, M. S. Han and K. S. Lee, Int. J. Precis. Eng. Man., 2013, 14(4), 679-690.

4 J. E. Martini, F. A. Waldman and N. P. Sud, SPE ANTEC Tech Papers, 1982, pp. 674-676.

5 M. Kobes, I. Helslootb, B. De Vries and J. G. Post, Fire Saf. J., 2010, 45(1), 1-11.

$6 \mathrm{X} . \mathrm{Mu}, \mathrm{B}$. Yuan, X. Feng, S. Qiu, L. Song and Y. Hu, $R S C A d v$., 2016, 6, 107.

7 H. Y. Ma, P. A. Song and Z. P. Fang, Sci. China: Chem., 2011, 54(2), 302-313.

8 P. G. Song, Z. H. Cao, Y. Z. Cai, L. P. Zhao, Z. P. Fang and S. Y. Fu, Polymer, 2011, 52(18), 4001-4010.

9 C. Y. Bao, Y. Q. Guo, B. H. Yuan, Y. Hu and L. Song, J. Mater. Chem., 2012, 22, 23057-23063.

10 A. Ameli, M. Nofar, C. B. Park, P. Pötschke and G. Rizvi, Carbon, 2014, 71(7), 206-217.

11 S. Kim, J. S. Oh, M. G. Kim, W. Jang, M. Wang, Y. Kim, H. W. Seo, Y. C. Kim, J. H. Lee, Y. Lee and J. D. Nam, ACS Appl. Mater. Interfaces, 2014, 6(20), 17647-17653.

12 C. Y. Bao, Y. Q. Guo, B. H. Yuan, Y. Hu and L. Song, J. Mater. Chem., 2012, 22, 23057-23063.

13 M. Zhao, L. H. Meng, L. C. Ma, L. N. Ma, X. B. Yang, Y. D. Huang, J. E. Ryu, A. Shankar, T. X. Li and C. Yan, Compos. Sci. Technol., 2018, 154, 28-36.

$14 \mathrm{~J}$. Zhang, M. Zuo, X. Lv, H. Zhang and Q. Zheng, RSC Adv., 2018, 8(26), 14579-14588.

15 M. H. Kang, H. Y. Yeom, H. Y. Na and S. J. Lee, Polymer, 2013, $37(4), 526-532$. 
16 L. X. Xu, J. W. Mcgraw, F. Gao, M. Grundy, Z. Ye, Z. Gu and J. L. Shepherd, J. Phys. Chem. C, 2013, 117(20), 10730-10742.

17 O. Rafeie, M. K. Razavi Aghjeh, A. Tavakoli, M. Salami Kalajahi and A. Jameie Oskooie, J. Appl. Polym. Sci., 2018, 46333.

18 X. Wang, Y. Hu, L. Song, H. Y. Yang, B. Yu, B. Kandola and D. Deli, Thermochim. Acta, 2012, 543, 156-164.
19 C. Bao, L. Song, C. A. Wilkie, B. H. Yuan, Y. Q. Guo, Y. Hu and X. L. Gong, J. Mater. Chem., 2012, 22(32), 16399-16406.

20 Z. C. He, M. Q. Zhong and J. T. Yang, J. Polym. Res., 2016, 12(23), 1-5.

21 D. Duan, H. Ye, N. Meng, C. Xu, B. Han, Y. Chen, M. Zhong and L. Xu, Carbon, 2018, 136(9), 417-429.

22 J. S. Colton and N. P. Suh, Polym. Eng. Sci., 1987, 27(7), 500503. 